\title{
Transkriptionskonventionen
}

Den in diesem Band versammelten Transkripten liegen i.d.R. die Konventionen des Gesprächsanalytischen Transkriptionssystems 2 (GAT 2, Selting et al. 2009) zugrunde. Die wichtigsten Konventionen sind im Folgenden aufgeführt.

\section{Sequenzielle Struktur/Verlaufsstruktur}

[ ]

Überlappungen und Simultansprechen

[]

$\begin{array}{ll}\text { Akzentuierung } & \\ \text { akZENT } & \text { Fokusakzent } \\ \text { ak!ZENT! } & \text { extra starker Akzent } \\ \text { akzEnt } & \text { Nebenakzent }\end{array}$

\section{Tonhöhenbewegung am Ende von Intonationsphrasen}

hoch steigend

mittel steigend

gleichbleibend

mittel fallend

tief fallend

\section{Ein- und Ausatmen}

${ }^{\circ} \mathrm{h} / \mathrm{h}^{\circ}$

Ein- bzw. Ausatmen von ca. 0.2-0.5 Sek. Dauer

${ }^{\circ} \mathrm{hh} / \mathrm{hh}^{\circ}$

Ein- bzw. Ausatmen von ca. 0.5-0.8 Sek. Dauer

${ }^{\circ} \mathrm{hhh} / \mathrm{hhh}^{\circ}$

Ein- bzw. Ausatmen von ca. 0.8-1.0 Sek. Dauer

\section{Pausen}

$($.

$(-)$

$(--)$

$(---)$

$(0.5)$
Mikropause, geschätzt, bis ca. 0.2 Sek. Dauer kurze geschätzte Pause von ca. 0.2-0.5 Sek. Dauer mittlere geschätzte Pause von ca. 0.5-0.8 Sek. Dauer längere geschätzte Pause von ca. 0.8-1.0 Sek. Dauer gemessene Pausen von ca. 0.5 bzw. 2.0 Sek. Dauer

\section{Sonstige segmentale Konventionen}

und_äh

äh öh äm

$=$
Verschleifungen innerhalb von Einheiten Verzögerungssignale, sog. „gefüllte Pausen“ schneller Anschluss neuer Sprecherbeiträge 
$\begin{array}{ll}: ;:: ;::: & \text { Dehnung, je nach Längung } \\ & (0.2-0.5,0.5-0.8,0.8-1.0 \text { Sek.) } \\ \text { ? } & \text { Abbruch durch Glottalverschluss }\end{array}$

Lachen und Weinen

haha hehe hihi

((lacht))

$<<$ lachend $>$ so, $>$

$<<:-)>$ so, $>$

Tonhöhensprünge

$\uparrow$

$\downarrow$ silbisches Lachen

Beschreibung des Lachens

Lachpartikeln in der Rede, mit Reichweite „smile voice“

\section{Lautstärke- und Sprechgeschwindigkeitsveränderungen, mit Extension \\ $<<f>>$ \\ $<<f>>$ \\ $<<\mathrm{p}>>$ \\ $<<\mathrm{pp}>>$ \\ $<<\mathrm{all}>>$ \\ $<<$ cresc $>>$ \\ $<<$ dim $>>$ \\ forte, laut \\ fortissimo, sehr laut \\ piano, leise \\ pianissimo, sehr leise \\ allegro, schnell \\ crescendo, lauter werdend \\ diminuendo, leiser werdend}

\section{Verändertes Tonhöhenregister, mit Extension \\ $<<\mathrm{t}>>$ \\ $<<\mathrm{h}\rangle>$ \\ tiefes Tonhöhenregister \\ hohes Tonhöhenregister}

\section{Rezeptionssignale}

\author{
$\mathrm{hm}$ ja nein nee \\ hm_hm ja_a \\ ?hmphm
}

einsilbige Signale

zweisilbige Signale

mit Glottalverschlüssen, meistens verneinend

\section{Sonstige Konventionen}

((hustet))

$<<$ hustend $>>$

$<<$ creaky $>>$

/ /

( ) para- und außersprachliche Handlungen und Ereignisse sprachbegleitende para- und außersprachliche Handlungen und Ereignisse mit Reichweite glottalisiert, „Knarrstimme“ rhythmische Einheit unverständliche Passage ohne weitere Angaben 
$(x x x),(x x x x x x) \quad$ ein bzw. zwei unverständliche Silben

(solche), (also/alo) vermuteter Wortlaut, mögliche Alternativen

$((.)$.

Auslassung im Transkript

l 1

simultane verbale und nonverbale Handlungen

desselben Sprechers 
